\title{
Communication \\ Comparison of Different Approaches Estimating Skeletal Muscle Oxygen Consumption Using Continuous-Wave Near-Infrared Spectroscopy at a Submaximal Contraction Level-A Comparative Study
}

\author{
Florian Kurt Paternoster ${ }^{1, *(\mathbb{D})}$ and Wolfgang Seiberl ${ }^{1,2} \mathbb{D}$ \\ 1 Department of Sport and Health Sciences, Biomechanics in Sports, Technical University of Munich (TUM), \\ 80992 Munich, Germany; wolfgang.seiberl@unibw.de \\ 2 Department of Human Sciences, Institute of Sport Science, Universität der Bundeswehr München, \\ 85579 Neubiberg, Germany \\ * Correspondence: florian.paternoster@tum.de
}

check for

updates

Citation: Paternoster, F.K.; Seiberl, W. Comparison of Different Approaches Estimating Skeletal Muscle Oxygen Consumption Using

Continuous-Wave Near-Infrared Spectroscopy at a Submaximal Contraction Level-A Comparative Study. Appl. Sci. 2022, 12, 2272. https://doi.org/10.3390/app12052272 Academic Editors: Maurizio Varanini, Alessandro Tonacci and Lucia Billeci

Received: 18 January 2022

Accepted: 17 February 2022

Published: 22 February 2022

Publisher's Note: MDPI stays neutral with regard to jurisdictional claims in published maps and institutional affiliations.

Copyright: (c) 2022 by the authors. Licensee MDPI, Basel, Switzerland. This article is an open access article distributed under the terms and conditions of the Creative Commons Attribution (CC BY) license (https:/ / creativecommons.org/licenses/by/ $4.0 /)$.
Featured Application: Authors are encouraged to provide a concise description of the specific application or a potential application of the work. This section is not mandatory.

\begin{abstract}
Continuous-wave near-infrared spectroscopy (CW-NIRS) is a method used to non-invasively estimate skeletal muscle oxygen consumption $\left(\mathrm{mVO}_{2}\right)$. Three different signals are provided by CW-NIRS devices: (1) oxygenated hemoglobin $\left(\mathrm{O}_{2} \mathrm{Hb}\right)$; (2) deoxygenated hemoglobin $(\mathrm{HHb})$; and (3) tissue saturation index (TSI). Typically, the signal's slope is interpreted with respect to high or low $\mathrm{mVO}_{2}$ during a muscle action. What signal (or combination of signals) is used for slope interpretation differs according to what approach is used, and there are several published in literature. It is unclear if resulting $\mathrm{mVO}_{2}$ estimates can be used interchangeably. Hence, this work aimed to compare five commonly used approaches on the same set of CW-NIRS data regarding their agreement in estimated $\mathrm{mVO}_{2}$. A controlled, lab-based study setting was used for this experiment. Data are based on isometric dorsiflexion contractions of 15 subjects at $30 \%$ of voluntary maximum torque, at two different ankle angles. CW-NIRS was placed on the $\mathrm{m}$. tibialis anterior and blood flow was occluded. The approaches for $\mathrm{mVO}_{2}$ estimation included calculations based on (1) TSI, (2) the difference between $\mathrm{O}_{2} \mathrm{Hb}$ and $\mathrm{HHb}$ (Hbdiff), (3) the mean of slopes from $\mathrm{O}_{2} \mathrm{Hb}$ and $\mathrm{HHb}$ ( $\mathrm{Hbmean}$ ), (4) the $\mathrm{HHb}$ signal, and (5) the $\mathrm{O}_{2} \mathrm{Hb}$ signal. Linear regression modelling was used to calculate respective slopes $\left(\mathrm{r}^{2}>0.99\right)$. Repeated measures ANOVA identified significant differences between the approaches $\left(p<0.001, \omega^{2}=0.258\right)$. Post-hoc tests revealed that only TSI vs. Hbmean and Hbdiff vs. $\mathrm{HHb}$ gave comparable results $(p>0.271)$. In addition, Bland-Altman plots showed good accuracy (mean bias $\sim 2 \%$ ) but low precision $( \pm 20 \%$ ) between the comparisons. Thus, the different approaches to estimate $\mathrm{mVO}_{2}$ cannot be used interchangeably. The results from different studies using different approaches should be compared with caution.
\end{abstract}

Keywords: skeletal muscle; oxidative metabolism; oxygenated hemoglobin; muscle action; tissue saturation index

\section{Introduction}

The primary method of energy production in skeletal muscle is the oxidative metabolism. Nowadays, near-infrared spectroscopy (NIRS) is one of the most used methods to noninvasively measure muscle oxygen consumption. Three different NIRS techniques are common on the market: the continuous-wave $(\mathrm{CW})$ technique, the frequency domain technique, and the time domain technique [1,2]. Regarding muscle metabolism during active motion, many scientists use the small, lightweight, and cost-efficient CW-NIRS [3-6]. 
A typical field of application is the estimation and comparison of muscle oxygen consumption $\left(\mathrm{mVO}_{2}\right)$ during different motion tasks, thereby covering a broad spectrum from basic research to applied studies in medicine and sport science [7-14]. The primary parameters of CW-NIRS are the oxygenated $\left(\mathrm{O}_{2} \mathrm{Hb}\right)$ and deoxygenated hemoglobin $(\mathrm{HHB})$ from small blood vessels and the total hemoglobin $\left(\mathrm{tHb}=\mathrm{O}_{2} \mathrm{Hb}+\mathrm{HHB}\right)$. In addition, using the spatially resolved spectroscopy method [15], it is possible to calculate the so-called tissue saturation index (TSI), reflecting the dynamic balance between $\mathrm{O}_{2}$ supply and $\mathrm{O}_{2}$ consumption [16]. Because CW-NIRS uses the assumption of a constant differential path length factor, it is not possible to measure the absolute concentration changes in HHB and $\mathrm{O}_{2} \mathrm{Hb}$. Instead, concentration changes are detected relative to a baseline assessed within a defined time period prior to muscle action [2,17].

CW-NIRS was found to be a reliable tool for measuring muscle oxygen consumption [18-21]. However, based on the same hardware and signal(s), three different post-processing options were crystalized to estimate $\mathrm{mVO}_{2}$ in active muscles: the slope method [22], the amplitude method [23], and the area under the curve method [24]. Agbangla et al. [25] concluded that the most sensitive, and hence the recommended, method is the calculation of the signal slope using linear regression.

Although there is agreement that the slope method can be considered the most sensitive approach, the CW-NIRS still comprises $\mathrm{O}_{2} \mathrm{Hb}, \mathrm{HHb}$, and TSI signals; thus, questions arise around which signal (or combination) should be used to analyze and interpret the linear slope. Different approaches are presented in literature., Some authors only used the $\mathrm{HHb}$ signal, as this signal is assumed to be less affected by a changing blood volume [26,27]. Others prefer the interpretation of the $\mathrm{O}_{2} \mathrm{Hb}$ signal [18], or the mean out of the slopes of $\mathrm{HHb}$ and $\mathrm{O}_{2} \mathrm{Hb}$ (HBmean) $[10,28,29]$. Additionally, some authors considered the difference between $\mathrm{O}_{2} \mathrm{Hb}$ and $\mathrm{HHb}$ (Hbdiff) [30,31]. Finally, Ferrari et al. [16] suggest using the TSI signal for the estimation of $\mathrm{mVO}_{2}$.

This shows that at least five different ways $\left(\mathrm{O}_{2} \mathrm{Hb}, \mathrm{HHb}\right.$, Hbdiff, $\mathrm{Hbmean}$, and TSI) to estimate the muscle oxygen consumption using CW-NIRS devices are commonly used in the literature. To the best of our knowledge, there is no information about the comparability of the outcomes of these methods regarding the estimated muscle oxygen consumption. This information is essential, for example, to ponder results and conclusions of different papers that used different approaches of CW-NIRS signal analysis. Hence, the aim of this paper was the comparison of the five presented methods to estimate the muscle oxygen consumption out of CW-NIRS.

\section{Materials and Methods}

\subsection{Subjects}

Fifteen male subjects ( $27 \pm 4 \mathrm{y}, 83 \pm 8 \mathrm{~kg}, 182 \pm 6 \mathrm{~cm}$ ) with no history of ankle joint injuries or neurological disorders took part in the study. The adipose tissue thickness of the $\mathrm{m}$. tibialis anterior was $5 \pm 2 \mathrm{~mm}$ and measured using a skinfold caliper.

\subsection{Experimental Setup}

Dorsiflexion torque was measured $(1000 \mathrm{~Hz}$ ) on a motor-driven dynamometer (IsoMed 2000, D\&R Ferstl GmbH, GER). Subjects lay backwards on the bench of the dynamometer, and the foot was fixed with belts and a tension belt to ensure constant positioning during the test session (Figure 1). The joint center of the ankle was carefully aligned with the rotational axis of the dynamometer. For the NIRS measurements, skin was shaved, cleaned, and disinfected. The device was placed on the muscle belly of the tibialis anterior (Figure 1). To avoid a displacement of the CW-NIRS device and to exclude the influence of ambient light, the measurement device was secured with adhesive tape in combination with an elastic bandage and covered with a light-tight piece of cloth. To guarantee standardized conditions regarding blood volume throughout the CW-NIRS measurements, venous and arterial occlusion was established using a pressure cuff $(400 \mathrm{mmHg}$, Hokanson 10D, Bellevue, WA, USA). The cuff was placed just above the knee and rapidly inflated $(\sim 3 \mathrm{~s})$ just prior to 
the onset of the submaximal contraction, and immediately deflated after the end of the submaximal trial. The position of the cuff was tagged with a permanent marker.

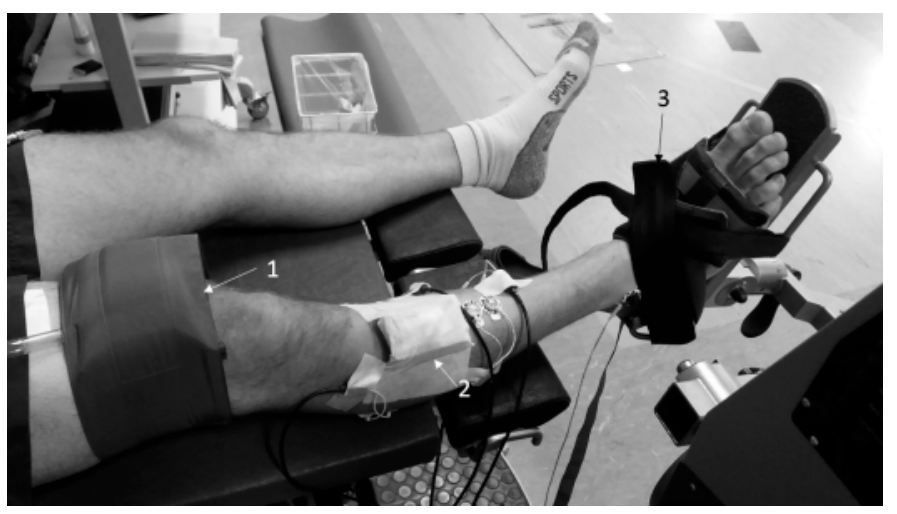

Figure 1. Experimental Setup. (1) Pressure cuff. (2) CW near-infrared spectroscopy device + adhesive tape. (3) Footrest including safety belts.

\subsection{Experimental Protocol}

To avoid familiarization effects and to train the reproducibility of steady submaximal torque production, subjects had to do a training session before the test session. The test session started with four maximum voluntary contractions (MVC) ( 3 s) at two different angular positions in a randomized order:

(1) Position_1: $3^{\circ}$ dorsiflexion;

(2) Position_2: $13^{\circ}$ plantarflexion, with $0^{\circ}$ defined as tibia axis perpendicular to the plantar aspect of the foot.

To ensure standardized conditions, the examiner always gave the same verbal starting command and provided maximal verbal encouragement during the MVCs. Participants had to contract as hard and fast as possible.

Subsequently to the MVCs, each subject had to perform six submaximal isometric contractions for $40 \mathrm{~s}$ at $30 \%$ of individually assessed maximum torque level (three at Position_1 and Position_2, respectively; randomized order). During contractions, torque feedback was provided on a screen in front of the subjects. Between every contraction, subjects rested as long as required; the minimum rest was set to 3 min [32].

\section{Near-Infrared Spectroscopy}

The local oxygen consumption of the tibialis muscle was estimated based on measurements with a CW-NIRS device (PortaMon, Artinis Medical Systems, Elst, The Netherlands) using a sample rate of $10 \mathrm{~Hz}$. The device consisted of three light sources and one light detector, and used wavelengths of 780 and $855 \mathrm{~nm}$. The maximal penetration depth was about $2 \mathrm{~cm}$ (distance light source - light detector $=4 \mathrm{~cm}$ ). The signals used in this study were $\mathrm{HHB}, \mathrm{O}_{2} \mathrm{Hb}$, TSI, and the total blood volume $\left(\mathrm{tHb}=\mathrm{HHB}+\mathrm{O}_{2} \mathrm{Hb}\right)$.

\subsection{Data Analysis}

CW-NIRS signals and torque/angle data were synchronized with an external device (PortaSync, Artinis Medical Systems, Elst, The Netherlands) and transferred to MATLAB (The Mathworks, Inc., Natick, MA, USA, version R2021a) for further analysis. Out of the three submaximal trials performed at each contraction condition, only the trial with the lowest standard deviation from the biofeedback torque target curve (30\% MVC) was chosen for further analysis. The torque and ankle joint signals were filtered using a fourth-order 5 $\mathrm{Hz}$ low-pass filter. 
For statistical analysis, the mean torque value for each trial was calculated over $25 \mathrm{~s}$. For normalization of the submaximal torque values, we used the highest peak torque value from the MVCs.

The estimation of the oxygen consumption was analyzed using five different approaches. The slope was calculated from:

(1) TSI signal;

(2) Difference between $\mathrm{O}_{2} \mathrm{Hb}$ and $\mathrm{HHb}$ (Hbdiff);

(3) Mean of the slopes from $\mathrm{O}_{2} \mathrm{Hb}$ and $\mathrm{HHb}$ (Hbmean);

(4) $\mathrm{HHb}$ signal;

(5) $\mathrm{O}_{2} \mathrm{Hb}$ signal.

The signals were smoothed using local regression smoothing (Loess smoothing, span $10 \%$ ). Using simple linear regression modelling, the linear part of the initial slope from the different approaches was defined $\left(r^{2}>0.99\right)$, representing the estimated oxygen consumption per second (Figure 2).
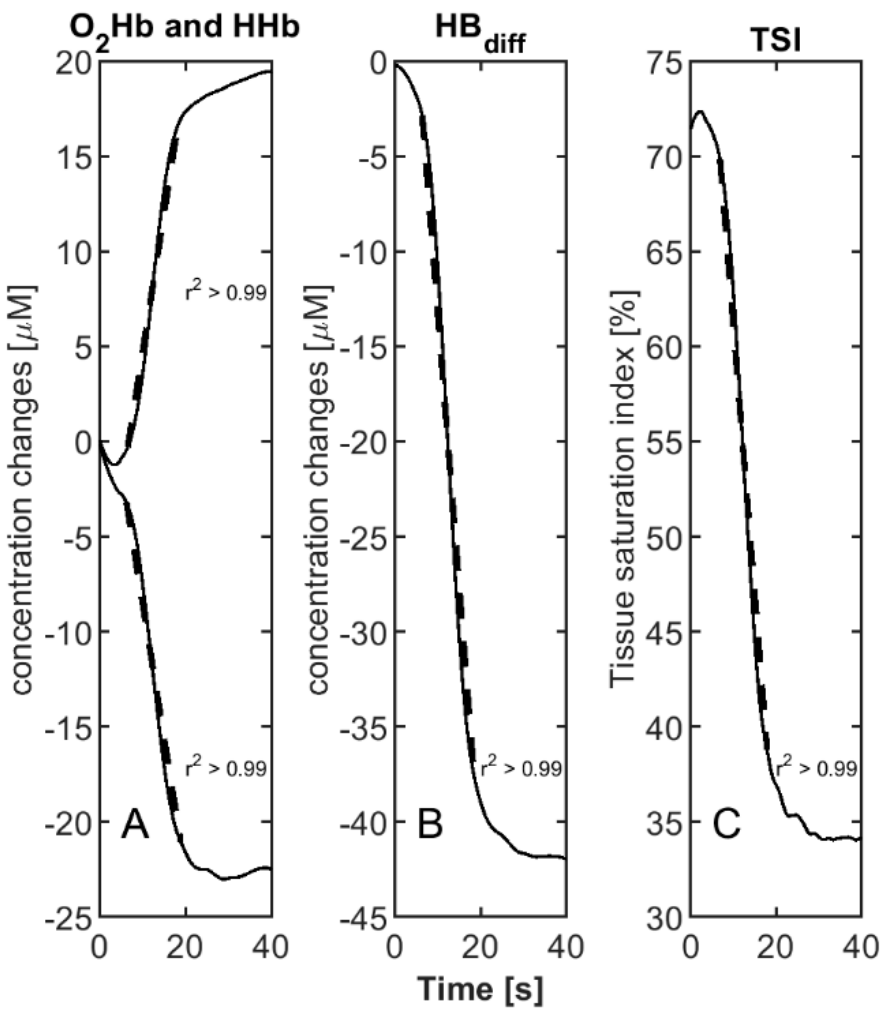

Figure 2. Exemplar data showing the five different approaches to estimate muscle oxygen consumption out of the initial slope using simple linear regression modelling (dashed lines, $\mathrm{r}^{2}>0.99$ ). (1) Slope of oxygenated hemoglobin (A: negative line). (2) Slope of deoxygenated hemoglobin (A: positive line). (3) Mean out of slope from oxygenated and deoxygenated hemoglobin (A). (4) Estimation of the slope out of the subtraction of oxygenated and deoxygenated hemoglobin (B). (5) Slope of the tissue saturation index $(\mathbf{C})$.

$\mathrm{mVO}_{2}$ was normalized using the respective delta value. The delta value was defined as the difference between the value at the onset of the contraction and the minimum (TSI, $\mathrm{Hbdiff}, \mathrm{HHb})$ or maximum $\left(\mathrm{O}_{2} \mathrm{Hb}\right)$ value that occurred during the contraction. In addition, we analyzed the $\mathrm{tHb}$ level to detect possible shifts in the blood volume during the analysis window. The analysis window represents the time between the start and end of the linear slope. This time window was split in two sections of equal length $(t 1, t 2)$. For both sections, a mean value was calculated. 


\subsection{Statistics}

For the different comparisons, normal distribution of the data was checked using the Shapiro-Wilk test. Torque and $\mathrm{tHb}$ levels were tested using a paired sample T-test including the Cohen's d effect size referencing 0.2 as small, 0.5 as medium, and $>0.8$ as large effect [33].

The comparability of $\mathrm{mVO}_{2}$ using the five different approaches was analyzed by a two-way repeated measures ANOVA (Position [2 levels]; Approaches [5 levels]) using $\omega^{2}$ as the effect size. If the sphericity was violated, Greenhouse-Geisser correction was used. Significant results were further analyzed using Bonferroni corrected post-hoc tests.

A $p$-value of $<0.05$ indicates a significant difference. For the post-hoc tests, Bonferronicorrected p-values are presented. The software JASP (version: 0.9) was used for the statistical analysis [34]. Data are presented as mean \pm standard deviation.

\section{Results}

The mean absolute torque value of Position_1 was significantly lower compared to Position_2 $(13.7 \pm 2.4$ vs. $15.6 \pm 3.0 \mathrm{Nm} ; \mathrm{t}(14)=-3.8, p=0.002, \mathrm{~d}:-0.988)$, resulting in a difference of $14.1 \pm 14.7 \%$. The submaximal individually normalized torque level was $30.5 \pm 2.9 \%$ MVC for Position_1 and 31.4 \pm 4.3\% MVC for Position_2.

Results for $\mathrm{tHb}$ showed significant differences between time windows of analysis $\mathrm{t} 1$ and $\mathrm{t} 2$ for all tested conditions $(p<0.001, \mathrm{~d}: \geq 1.754)$, reaching a maximum difference of 1.8 $\pm 0.9 \mu \mathrm{M}$ for the $\mathrm{O}_{2} \mathrm{Hb}$ condition at Position_1 (Figure 3).

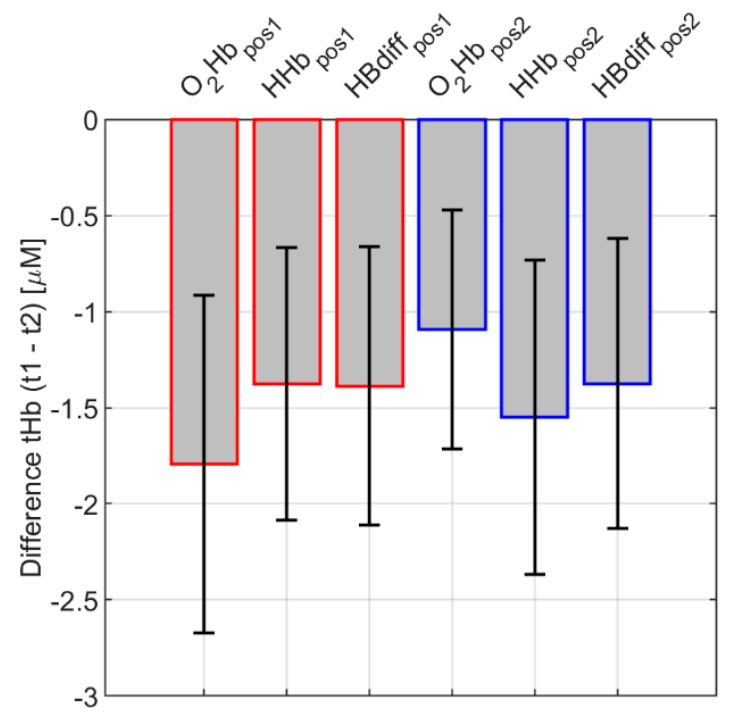

Figure 3. Difference of total hemoglobin $(\mathrm{tHb})$. The difference was calculated by dividing the slope analysis time into to equal halves $(t 1, t 2)$ and subtracting the mean value of $t 1$ from $t 2$. Results for $\mathrm{tHb}$ showed significant differences between time windows of analysis $\mathrm{t} 1$ and $\mathrm{t} 2$ for all tested conditions $(p<0.05, \mathrm{~d}: \geq 1.754)$. Pos_1 $=\sim 3^{\circ}$ dorsiflexion [red edging]. Pos_2 $=\sim 13^{\circ}$ plantarflexion [blue edging].

Slope analysis of the NIRS data showed a main effect for the different approaches $\left(\mathrm{F}(1.8,25.7)=51.62, p<0.001, \omega^{2}=0.258\right)$, whereas the ankle joint position $(\mathrm{F}(1,14)=0.04$. $p=0.847$ ) did not influence $\mathrm{mVO}_{2}$ data (Figure 4).

The post-hoc analysis for the different approaches showed significant differences for all comparisons ( $\left.p_{\text {bonf }}<0.02\right)$, except for TSI vs. HBmean $\left(t=2.469\right.$. $p_{\text {bonf }}=0.271$ ) and Hbdiff vs. $\mathrm{HHb}\left(\mathrm{t}=0.013\right.$. $\left.\mathrm{p}_{\text {bonf }}=1.000\right)($ Table 1$)$. 


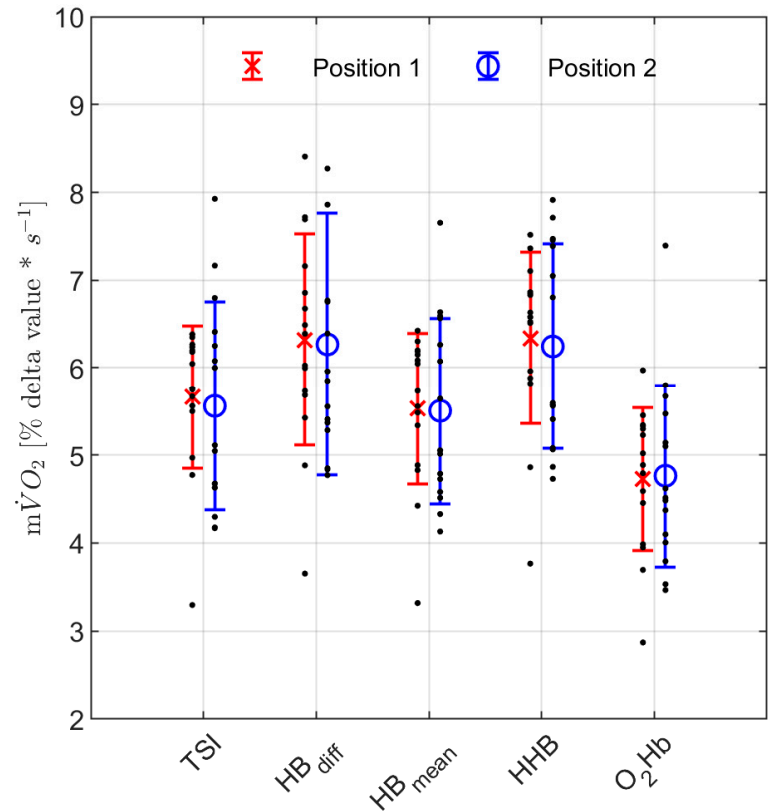

Figure 4. Estimated oxygen consumption $\left(\mathrm{mVO}_{2}\right)$ at the different angular positions (Position_1, Position_2) using five different approaches. Data represents mean \pm standard deviation. TSI = tissue saturation index. HBdiff = difference between $\mathrm{O}_{2} \mathrm{Hb}$ and $\mathrm{HHb}$. HBmean = mean slope out of the slopes from oxygenated and deoxygenated signal. $\mathrm{HHb}=$ deoxygenated signal. $\mathrm{O}_{2} \mathrm{Hb}=$ oxygenated signal. Note: black dots represent individual data.

Table 1. Overview of Bonferroni corrected post-hoc results ( $\mathrm{p}_{\text {bonf }}$ ) for the main effect approaches and the percentage difference ( \pm standard deviation) of the comparisons.

\begin{tabular}{cccc}
\hline & & pbonf $_{\text {b }}$ & Difference [\%] \\
\hline TSI & HBdiff & 0.020 & $12.5 \pm 11.2$ \\
\hline & $\mathrm{HBmean}$ & 0.271 & $2.4 \pm 1.9$ \\
\hline $\mathrm{HHb}$ & $<0.001$ & $12.3 \pm 6.0$ \\
\hline & $\mathrm{O}_{2} \mathrm{Hb}$ & $<0.001$ & $15.5 \pm 4.7$ \\
\hline $\mathrm{HBmean}$ & 0.002 & $11.6 \pm 7.4$ \\
\hline $\mathrm{HBmean}$ & $\mathrm{HHb}$ & 1.000 & $7.2 \pm 5.2$ \\
\hline & $\mathrm{O}_{2} \mathrm{Hb}$ & $<0.001$ & $24.1 \pm 7.7$ \\
\hline $\mathrm{HHb}$ & $\mathrm{HHb}$ & $<0.001$ & $14.1 \pm 4.7$ \\
\hline & $\mathrm{O}_{2} \mathrm{Hb}$ & $<0.001$ & $14.1 \pm 4.7$ \\
\hline & $\mathrm{O}_{2} \mathrm{Hb}$ & $<0.001$ & $24.5 \pm 7.3$ \\
\hline
\end{tabular}

Using these results, Bland-Altman plots were created, calculating the mean out of those approaches with no significant differences (TSI vs. HBmean, HBdiff vs. $\mathrm{HHb}$ ) to reduce the amount of data (Figure 5).

Bland-Altman analysis showed the biggest bias for the comparison of TSI and Hbmean vs. Hbdiff and $\mathrm{HHB}(-1.9 \%)$, whereas the biggest range was found for Hbdiff and $\mathrm{HHb}$ vs. $\mathrm{O}_{2} \mathrm{Hb}(20.4 \%)$ (Table 2). 

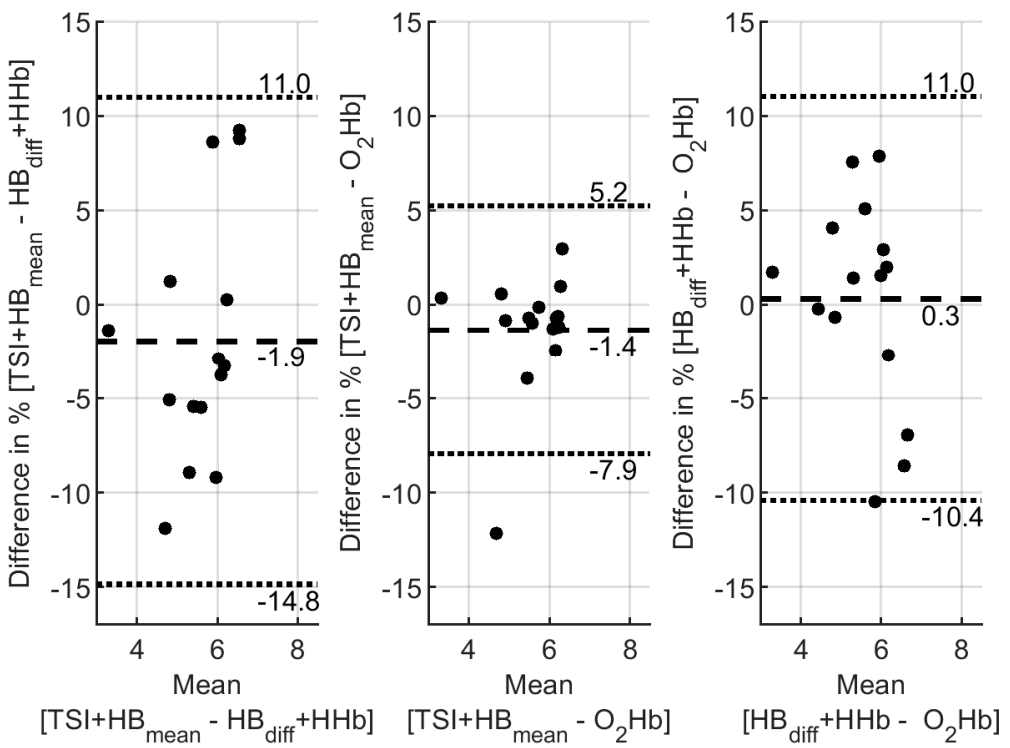

Figure 5. Bland-Altman plots. Left plot: comparison of TSI + HBmean and HBdiff $+\mathrm{HHb}$. Middle plot: comparison of TSI + HBmean and $\mathrm{O}_{2} \mathrm{Hb}$. Right plot: comparison of HBdiff $+\mathrm{HB}$ and $\mathrm{O}_{2} \mathrm{Hb}$. Note: dashed horizontal line represents the bias [\%] and dotted horizontal line represents the limits of agreement $( \pm 1.96 \mathrm{SD})$ of the respective comparison. For parameters with a plus sign (e.g., TSI + HBmean), the mean value was calculated because statistics showed no significant differences between those parameters.

Table 2. Results of the Bland-Altman plots comparing the different methods.

\begin{tabular}{cccc}
\hline & Bias [\%] & LoA [\%] & Range [\%] \\
\hline TSI and Hbmean-Hbdiff and $\mathrm{HHb}$ & -1.9 & $11 /-14.8$ & 12.9 \\
\hline TSI and Hbmean- $\mathrm{O}_{2} \mathrm{Hb}$ & -1.4 & $5.2 /-7.9$ & 6.6 \\
\hline Hbdiff and $\mathrm{HHb}-\mathrm{O}_{2} \mathrm{Hb}$ & 0.3 & $11.0 /-10.4$ & 20.4 \\
\hline
\end{tabular}

LoA = limits of agreement.

\section{Discussion}

The goal of this study was to identify possible differences between common approaches based on the CW-NIRS signal slope to estimate the muscle oxygen consumption, which is of special interest when, e.g., discussing the outcome of a study in the context of existing literature. Five slope-based approaches were analyzed that either use a single signal $\left(\mathrm{HHb}, \mathrm{O}_{2} \mathrm{Hb}\right)$ or a combination of different signals provided by the CW-NIRS device (TSI, HBdiff, HBmean).

This study showed significant differences between three out of the five analyzed approaches to estimate muscle oxygen consumption of the same contraction data. More precisely, differences were found between all approaches except for TSI vs. HBmean as well as HBdiff vs. $\mathrm{HHb}$. However, $\mathrm{O}_{2} \mathrm{Hb}$ always differed from the other approaches resulting in an underestimation of $\mathrm{mVO}_{2}$ values and additionally showed the biggest percentage difference (Table 1) compared to the rest. The difference between $\mathrm{O}_{2} \mathrm{Hb}$ and $\mathrm{HHb}$ is particularly unexpected. This study used a pressure cuff to exclude blood volume changes in the region of interest. In such a closed system, the $\mathrm{O}_{2} \mathrm{Hb}$ and $\mathrm{HHb}$ signals are assumed to be mirrored and, hence, should have the same absolute slope [11]. Having alterations of blood volume can influence the estimated $\mathrm{mVO}_{2}$. In literature, this has been described as an increase in $\mathrm{tHb}[21,28,35]$. However, the analysis showed that this was not the case and, instead of an increase in blood volume, there was a decrease in blood volume (Figure 3). Similar trends are shown in De Ruiter et al. (Figure 4 in [28]). With a maximum difference of $1.8 \mu \mathrm{M}$ in the current analysis, the observed differences are quite small and, therefore, 
can be assumed to be negligible, though they are statistically conspicuous. Consequently, these differences in $\mathrm{tHb}$ cannot explain the differences observed in $\mathrm{mVO}_{2}$.

Despite significant absolute differences, the question concerning the relative agreement of the different approaches remains. The bias between the comparisons reached a maximum of $\sim 2 \%$, revealing a good accuracy between the different approaches. Besides this, the limits of agreement showed a broader range across the comparisons, identifying the least precision for $\mathrm{HBdiff}$ and $\mathrm{HHb}$ vs. $\mathrm{O}_{2} \mathrm{Hb}$. For this comparison, $95 \%$ of the observations were within a range of $\pm 20.4 \%$. On the other hand, TSI and HBmean vs. $\mathrm{O}_{2} \mathrm{Hb}$ showed a small bias accompanying the highest precision. Hence, $\mathrm{O}_{2} \mathrm{Hb}$ underestimated the values; however, $95 \%$ of the observations were within a range of $\pm 6.6 \%$.

A limitation of this study is that we only used one submaximal intensity to estimate oxygen consumption. Therefore, it remains unclear if these observed differences regarding the estimated oxygen consumption are the same across different intensity levels. In the literature there are several papers published investigating the amount of oxygen consumption across different intensity levels using different muscle groups and incremental steps of $10 \%[11,21,36,37]$. The authors showed that $\mathrm{mVO}_{2}$ increased with increasing contraction intensity, which is logical as a higher contraction intensity implies additional motor unit recruitment and increased firing rates. Van Beekvelt et al. [21] and Hamaoka et al. [36] used a handgrip exercise and found a linear increase in $\mathrm{mVO}_{2}$ up to $\sim 20-40 \% \mathrm{MVC}$. In contrast, Praagman et al. [37], using a bigger muscle group (elbow flexors), concluded a linear increase in muscle oxygen consumption across a broader range of loads $(0-70 \%$ force level). In addition, De Ruiter et al. ([11], see Figure 5), also show a constant increase in $\mathrm{mVO}_{2}$ across the different contraction levels up to $\sim 75 \% \mathrm{MVC}$. De Ruiter et al. [11] analyzed the different superficial parts of the quadriceps femoris at different angular positions and, therefore, investigated a muscle group of the lower limb that is used in daily activities, such as walking similar to tibialis anterior. Based on these findings in the literature, it can be presumed that the differences in the various approaches for estimating $\mathrm{mVO}_{2}$, as presented for one intensity in this study, persist over a broader range of contraction levels, at least where $\mathrm{mVO}_{2}$ was found to increase linearly with increasing muscle activation.

In conclusion, we compared five commonly used approaches to estimate the muscle oxygen consumption based on the same set of CW-NIRS data. Although Bland-Altman plots showed good accuracy between the different approaches, the precision revealed high deviations and statistics identified significant differences for three out of the five approaches. Thus, comparisons across different CW-NIRS studies need to be conducted with caution if different approaches were used for the estimation $\mathrm{mVO}_{2}$ consumption.

Author Contributions: F.K.P. and W.S. conceived and designed the experiments. F.K.P. performed the experiments. F.K.P. analyzed the data. All authors discussed the results and contributed to the elaboration of the manuscript. All authors have read and agreed to the published version of the manuscript.

Funding: This research received no external funding.

Institutional Review Board Statement: The study was conducted in accordance with the Declaration of Helsinki and approved by the local Ethics Committee of the Technical University of Munich (protocol code: 2539/13).

Informed Consent Statement: Informed consent was obtained from all subjects involved in the study.

Data Availability Statement: The data presented in this study are openly available in the repository of the Technical University of Munich using the following link: https:/ / mediatum.ub.tum.de/1519453 (last accessed: 17 January 2022).

Conflicts of Interest: The authors declare no conflict of interest. 


\section{References}

1. Scholkmann, F.; Kleiser, S.; Metz, A.J.; Zimmermann, R.; Mata Pavia, J.; Wolf, U.; Wolf, M. A review on continuous wave functional near-infrared spectroscopy and imaging instrumentation and methodology. Neuroimage 2013, 85, 6-27. [CrossRef] [PubMed]

2. Barstow, T.J. Understanding near infrared spectroscopy and its application to skeletal muscle research. J. Appl. Physiol. 2019, 126, 1360-1376. [CrossRef] [PubMed]

3. Zhang, C.; Hodges, B.; McCully, K.K. Reliability and reproducibility of a four arterial occlusions protocol for assessing muscle oxidative metabolism at rest and after exercise using near-infrared spectroscopy. Physiol. Meas. 2020, 41, 65002 [CrossRef] [PubMed]

4. Shaw, K.; Butcher, S.; Ko, J.; Zello, G.A.; Chilibeck, P.D. Wearing of Cloth or Disposable Surgical Face Masks has no Effect on Vigorous Exercise Performance in Healthy Individuals. Int. J. Environ. Res. Public Health 2020, 17, 8110. [CrossRef]

5. Baláš, J.; Gajdošík, J.; Giles, D.; Fryer, S.; Krupková, D.; Brtník, T.; Feldmann, A. Isolated finger flexor vs. exhaustive whole-body climbing tests? How to assess endurance in sport climbers? Eur. J. Appl. Physiol. 2021, 121, 1337-1348. [CrossRef]

6. Stöggl, T.; Born, D.-P. Near Infrared Spectroscopy for Muscle Specific Analysis of Intensity and Fatigue during Cross-Country Skiing Competition-A Case Report. Sensors 2021, 21, 2535. [CrossRef]

7. Zuccarelli, L.; do Nascimento Salvador, P.C.; Del Torto, A.; Fiorentino, R.; Grassi, B. Skeletal muscle Vo2 kinetics by the NIRS repeated occlusions method during the recovery from cycle ergometer exercise. J. Appl. Physiol. 2020, 128, 534-544. [CrossRef]

8. Malagoni, A.M.; Felisatti, M.; Lamberti, N.; Basaglia, N.; Manfredini, R.; Salvi, F.; Zamboni, P.; Manfredini, F. Muscle oxygen consumption by NIRS and mobility in multiple sclerosis patients. BMC Neurol. 2013, 13, 52. [CrossRef]

9. Vardi, M.; Nini, A. Near-infrared spectroscopy for evaluation of peripheral vascular disease. A systematic review of literature. Eur. J. Vasc. Endovasc. Surg. 2008, 35, 68-74. [CrossRef]

10. Paternoster, F.K.; Hahn, D.; Stöcker, F.; Schwirtz, A.; Seiberl, W. Oxygen consumption of gastrocnemius medialis muscle during submaximal voluntary isometric contractions with and without preceding stretch. Sci. Rep. 2017, 7, 77. [CrossRef]

11. De Ruiter, C.J.; de Boer, M.D.; Spanjaard, M.; de Haan, A. Knee angle-dependent oxygen consumption during isometric contractions of the knee extensors determined with near-infrared spectroscopy. J. Appl. Physiol. 2005, 99, 579-586. [CrossRef] [PubMed]

12. Perrey, S.; Ferrari, M. Muscle Oximetry in Sports Science: A Systematic Review. Sports Med. 2018, 48, 597-616. [CrossRef] [PubMed]

13. Booghs, C.; Baudry, S.; Enoka, R.; Duchateau, J. Influence of neural adjustments and muscle oxygenation on task failure during sustained isometric contractions with elbow flexor muscles. Exp. Physiol. 2012, 97, 918-929. [CrossRef] [PubMed]

14. Boone, J.; Celie, B.; Dumortier, J.; Barstow, T.J.; de Bleecker, J.; Smet, J.; van Lander, A.; van Coster, R.; Bourgois, J. Forearm muscle oxygenation responses during and following arterial occlusion in patients with mitochondrial myopathy. Respir. Physiol. Neurobiol. 2014, 190, 70-75. [CrossRef]

15. Suzuki, S.; Takasaki, S.; Ozaki, T.; Kobayashi, Y. Tissue oxygenation monitor using NIR spatially resolved spectroscopy. Proc. SPIE 1999, 3597, 582-592. [CrossRef]

16. Ferrari, M.; Muthalib, M.; Quaresima, V. The use of near-infrared spectroscopy in understanding skeletal muscle physiology: Recent developments. Philos. Trans. A Math. Phys. Eng. Sci. 2011, 369, 4577-4590. [CrossRef]

17. Ferrari, M. Progress of near-infrared spectroscopy and topography for brain and muscle clinical applications. J. Biomed. Opt. 2007, 12, 62104. [CrossRef]

18. Lacroix, S.; Gayda, M.; Gremeaux, V.; Juneau, M.; Tardif, J.-C.; Nigam, A. Reproducibility of near-infrared spectroscopy parameters measured during brachial artery occlusion and reactive hypermia in healthy men. J. Biomed. Opt. 2012, 17, 077010. [CrossRef]

19. Muthalib, M.; Millet, G.Y.; Quaresima, V.; Nosaka, K. Reliability of near-infrared spectroscopy for measuring biceps brachii oxygenation during sustained and repeated isometric contractions. J. Biomed. Opt. 2010, 15, 17008. [CrossRef]

20. Crenshaw, A.G.; Elcadi, G.H.; Hellstrom, F.; Mathiassen, S.E. Reliability of near-infrared spectroscopy for measuring forearm and shoulder oxygenation in healthy males and females. Eur. J. Appl. Physiol. 2012, 112, 2703-2715. [CrossRef]

21. van Beekvelt, M.C.; van Engelen, B.G.; Wevers, R.A.; Colier, W.N. In vivo quantitative near-infrared spectroscopy in skeletal muscle during incremental isometric handgrip exercise. Clin. Physiol. Funct. Imaging 2002, 22, 210-217. [CrossRef] [PubMed]

22. Quaresima, V.; Colier, W.N.; van der Sluijs, M.; Ferrari, M. Nonuniform quadriceps $\mathrm{O}_{2}$ consumption revealed by near infrared multipoint measurements. Biochem. Biophys. Res. Commun. 2001, 285, 1034-1039. [CrossRef] [PubMed]

23. Celie, B.; Boone, J.; van Coster, R.; Bourgois, J. Reliability of near infrared spectroscopy (NIRS) for measuring forearm oxygenation during incremental handgrip exercise. Eur. J. Appl. Physiol. 2012, 112, 2369-2374. [CrossRef] [PubMed]

24. Manfredini, F.; Malagoni, A.M.; Felisatti, M.; Mandini, S.; Mascoli, F.; Manfredini, R.; Basaglia, N.; Zamboni, P. A dynamic objective evaluation of peripheral arterial disease by near-infrared spectroscopy. Eur. J. Vasc. Endovasc. Surg. 2009, 38, 441-448. [CrossRef] [PubMed]

25. Agbangla, N.F.; Audiffren, M.; Albinet, C.T. Assesing muscular oxygenation during incremental excercise using near-infrares spectrosscopy: Comparison of three different methods. Physiol. Res. 2017, 66, 979-985. [CrossRef]

26. De Blasi, R.A.; Cope, M.; Elwell, C.; Safoue, F.; Ferrari, M. Noninvasive measurement of human forearm oxygen consumption by near infrared spectroscopy. Europ. J. Appl. Physiol. 1993, 67, 20-25. [CrossRef]

27. Ryan, T.E.; Erickson, M.L.; Brizendine, J.T.; Young, H.-J.; McCully, K.K. Noninvasive evaluation of skeletal muscle mitochondrial capacity with near-infrared spectroscopy: Correcting for blood volume changes. J. Appl. Physiol. 2012, 113, 175-183. [CrossRef] 
28. De Ruiter, C.J.; Goudsmit, J.F.A.; van Tricht, J.A.; de Haan, A. The isometric torque at which knee-extensor muscle reoxygenation stops. Med. Sci. Sports Exerc. 2007, 39, 443-453. [CrossRef]

29. Kooistra, R.D.; Blaauboer, M.E.; Born, J.R.; De Ruiter, C.J.; de Haan, A. Knee extensor muscle oxygen consumption in relation to muscle activation. Eur. J. Appl. Physiol. 2006, 98, 535-545. [CrossRef]

30. Ufland, P.; Lapole, T.; Ahmaidi, S.; Buchheit, M. Muscle force recovery in relation to muscle oxygenation. Clin. Physiol. Funct. Imaging 2012, 32, 380-387. [CrossRef]

31. Van Beekvelt, M.; Colier, W.N.J.M.; Wevers, R.A.; van Engelen, B.G.M. Performance of near-infrared spectroscopy in measuring local O2 consumption and blood flow in skeletal muscle. J. Appl Physiol. 2001, 90, 511-519. [CrossRef] [PubMed]

32. De Salles, B.F.; Simão, R.; Miranda, F.; Novaes, J.d.S.; Lemos, A.; Willardson, J.M. Rest interval between sets in strength training. Sports Med. 2009, 39, 765-777. [CrossRef] [PubMed]

33. Cohen, J. Statistical Power Analysis for the Behavioral Sciences, 2nd ed.; Erlbaum: Hillsdale, NJ, USA, 1988; ISBN 0-8058-0283-5.

34. JASP Team. JASP (Version 0.11.1) [Computer Software]. 2019. Available online: https://jasp-stats.org/ (accessed on 17 January 2022).

35. Ferrari, M.; Binzoni, T.; Quaresima, V. Oxidative Metabolism in Muscle. Phil. Trans. R. Soc. Lond. B 1997, 1354, 677-683. [CrossRef] [PubMed]

36. Hamaoka, T.; Iwane, H.; Shimomitsu, T.; Katsumura, T.; Murase, N.; Nishio, S.; Osada, T.; Kurosawa, Y.; Chance, B. Noninvasive measures of oxidative metabolism on working human muscles by near-infrared spectroscopy. J. Appl. Physiol. 1996, 81, 1410-1417. [CrossRef]

37. Praagman, M.; Veeger, H.; Chadwick, E.; Colier, W.; van der Helm, F. Muscle oxygen consumption, determined by NIRS, in relation to external force and EMG. J. Biomech. 2003, 36, 905-912. [CrossRef] 